\title{
Light Imprint New Urbanism - a framework for urban and environmental sustainability
}

\author{
T. E. Low ${ }^{1}$, G. Tachiev ${ }^{2}$, P. Kelly ${ }^{1}$, G. Pearlman ${ }^{1}$, N. Black ${ }^{1}$, \\ M. Carney ${ }^{1} \&$ L. Koutrelakos ${ }^{1}$ \\ ${ }^{I}$ DPZ Charlotte's Office, USA \\ ${ }^{2}$ Florida International University, USA
}

\begin{abstract}
Light Imprint New Urbanism (LINU) is a comprehensive planning and development framework that emphasizes sustainability, pedestrian-oriented design and increased environmental and infrastructural efficiency, while reducing a community's anticipated construction expenses by up to one third of conventional practices. On a regional scale, building compact urban entities reduces the stress and fragmentation of the watershed caused by roads, infrastructure and impervious cover. This strategy preserves the resources provided by the watershed and creates environmentally sustainable communities. On a community and building scale, Light Imprint development makes communities more economically vital by reducing infrastructure such as roads, public works and facilities. The implementation of Light Imprint methods also results in a smaller ecological footprint of individual buildings. The hydrological effects include decreased storm water runoff in terms of total volume, peak capacity and enhanced groundwater recharge, all of which are critical factors for sustaining stream flow and as a result a considerably lower flood and erosion potential due to induced changes of the environment.
\end{abstract}

Keywords: Light Imprint urbanism, sustainable urbanism, environmental sustainability, climate change.

\section{Introduction}

The continuous expansion of the infrastructure of the human society increases the stress and impacts the natural, sustainable conditions of the watersheds. The impacts of urbanization on watersheds is mostly caused by impervious cover and 
results in elevated levels of water, air and soil pollution, deterioration of the ecosystem and decreasing biodiversity. Green Urbanism (GU) is one alternative environmental approach promoted by landscape architects which emphasizes an increased percentage of open space within a development site, typically in the range of $60 \%$ or greater per project, however streets are often terminated to prevent encroachment on greenway fingers and decrease the economic feasibility of the project by reserving significant open space. Low Impact Development (LID) $[1,2]$ is another popular environmental development strategy adopted by some municipalities. The origins of LID are found in conventional suburban development and include stormwater management techniques that filter, store, and detain runoff close to water bodies, including open space conservation, buffers and grass rooftops [1]. LID prioritizes various environmental factors over urban planning principles and may as a result promote sprawl development patterns by ignoring such important requirements as connectivity, compactness, walkability, and mixed-use. On-site design techniques, such as Best Management Practices (BMP) are used by LID for improving stormwater quality and proposed by the EPA [3]. BMP's typically focus on engineering and water quality issues of stormwater runoff rather than planning and design for addressing methods for stormwater treatment. This approach can harm a community's social connectivity and possibly interfere with retail merchandizing needs and feasibility. In recent years, the development industry has begun to shift from the conventional suburban model towards the New Urban model, which advocates the development of compact, mixed-use, pedestrian friendly communities. Much of this shift has emerged from the need to better address environmental and community goals and to reconcile the development industry with land conservation organizations. The New Urban model first developed in the 80's by Duany Plater - Zyberk \& Company (www.dpz.com) allows residents to greatly decrease use of their cars, clearly yield environmental benefits, but such developments also have a great number of other environmental strengths.

One of the greatest strength of the New Urbanism in the area of sustainability is the design of compact communities, which have a better performance on the regional scale for two important reasons. First, compact communities require reduced infrastructure, and second, they cause lower stress and fragmentation originating from impervious cover. The significance of compactness has been shown in a recent study by Long et al [4], which used US Census 2000 data [5] to analyze 5 cities within the Miami Metropolis, including Coral Gables, Doral, Hialeah, Miami and Sweetwater. The study included 281 Census Blocks with population of 384,134 on 31,617 acres of land.

For each census block the population density was determined by dividing population by area of census block and the area of roads per population was determined dividing the total area of roads per population (Figure 1), which resulted in a logarithmic trend. The figure illustrates the extent of infrastructure expressed in terms of roads needed per person as a function of the population density. The need for roads per person grows logarithmically as the density decreases. While not shown here, similar is the effect on vehicle miles traveled and infrastructure costs of other public works such as water, sewer and power lines. 


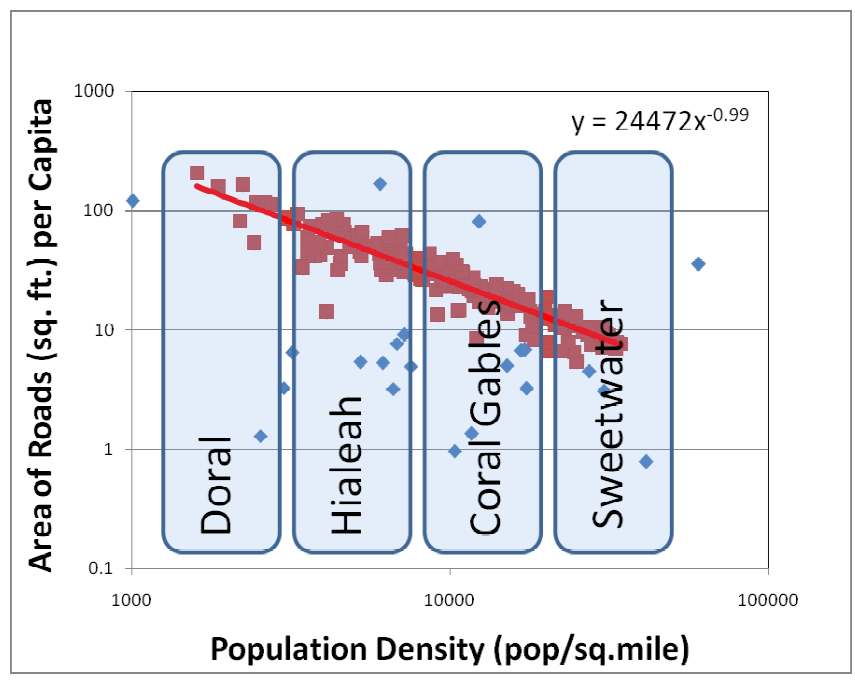

Figure 1: $\quad$ Effect of population density on road sharing.

\section{Light Imprint New Urbanism}

Further supporting the concepts of urban sustainability, there are newly developed techniques for "Light Imprint New Urbanism" (LINU) [6], which aim to "lie lightly on the land" by coordinating engineering practices and New Urbanist design practices. It enables developers to consider environmental and preservation factors without compromising design priorities such as connectivity and the public realm. Like all New Urban planning, LINU respects site terrain and topography while it prioritizes public civic space. Additionally, LINU offers a range of cutting-edge environmental strategies for differing landscapes and urban conditions. LINU planning introduces a tool set that deals with stormwater run-off through natural drainage, conventional engineering infrastructure, and innovative infiltration practices. These tools are to be used collectively at the sector, neighborhood, and block scale. The combination of tools are adjusted according to the appropriateness of their use in each transect zone. This toolset not only offers a great range of environmental benefits, but can also significantly lower construction and engineering costs. By using different tools in each transect zone, LINU is not limited to a single approach for environmentally sensitive development. Rather, it offers a range of context-sensitive design solutions that ultimately work together on the community level. Thus LINU reduces infrastructure on the neighborhood scale in terms of roads, public works and facilities. On the block scale, the implementation of Light Imprint methods results in reduced ecological footprint of individual buildings and reduced stormwater runoff.

Griffin Park, a DPZ-designed traditional neighborhood development in Greenville, South Carolina, offers one example of Light Imprint New Urban development. The area has been heavily developed as the city has expanded, and 
much of the land surrounding the site has been developed into conventional housing subdivisions. Griffin Park will offer an alternative to this sprawl development, and will give residents a chance to live in a more communityoriented atmosphere with public space, recreational offerings, and retail within walking distance of their homes. When completed, Griffin Park will include more than one thousand single-family homes as well as large-scale retail offerings. The majority of the retail activity will be within the town center at the major intersection, which was originally zoned for big-box retail development. The big-box components have been re-designed to be integrated with a pedestrian-scaled Main Street, lined with smaller-scaled retail establishments and live/work units. This Main Street development spine will connect the various neighborhoods, each of which will have its own smaller community center featuring a plaza or a square. Additionally, each neighborhood will have a unique landscape character and design adhering to the site's topography and natural features. Beyond Griffin Park's town center, larger single-family houses are interspersed with townhouses and carriage houses along streets designed for pedestrian activity. Many of these streets follow the curves of the Reedy River, preserving the site's wetlands and providing a buffer to nearby development.

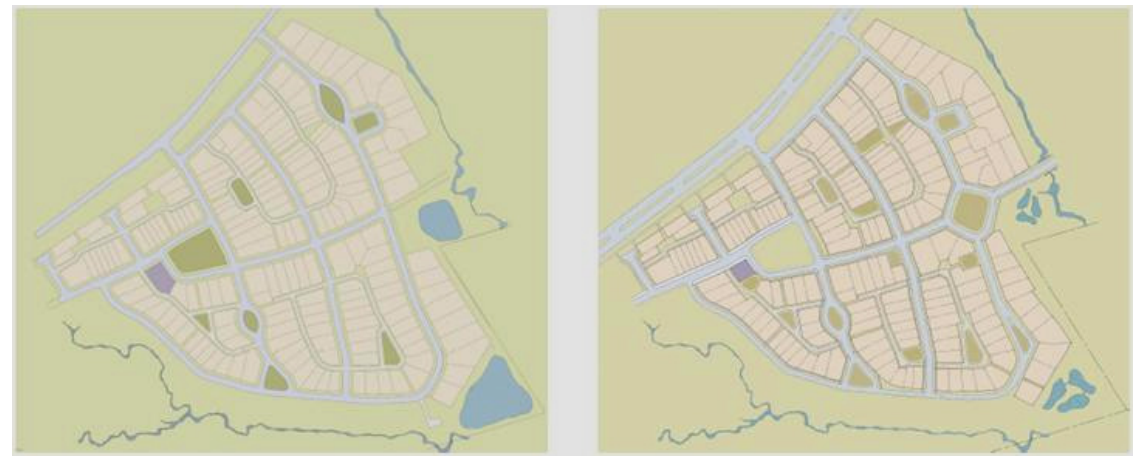

Figure 2: $\quad$ Master plan of Griffin Park, left image represents Conventional TND Master plan and the right image represents Light Imprint TND Master Plan.

The figure above compares the master plan before and after the application of Light Imprint engineering. Landscape architect Guy Pearlman and designer Patrick Kelly, both of the DPZ Charlotte office developed the LINU model for Griffin Park to create an environmentally sensitive community, preserve mature tree stands, and lower the construction costs for the first development phase. The conventional TND engineering plan is engineered for both county review and bidding purposes; it reaches an extensive level of detail. The light-imprint engineering plan is based on many of the variables developed in the conventional plan. Added consideration, however, is given to environmental and preservation factors. Environmental strategies at Griffin Park included the introduction of rain gardens and a tree protection fence. The introduction of these elements allowed 
for the development's underground piping system as well as curbs and gutters to be downsized thereby lessening the environmental impact of the development and saving significant sums on construction. The town plan also preserves green space by including public civic spaces such as parks, playgrounds, trails, and sports areas. By preserving open space as well as serving as an example of compact, mixed-use development, Griffin Park is envisioned as a precedent for how the Greenville area can accommodate further growth.

In order to achieve the desired goals of the light-imprint TND plan, a tree protection fence is introduced in the erosion control phase to protect the existing mature trees. That strategy results in a $27 \%$ cost increase when compared with the conventional proposed method. Yet, a cost saving between the two methods was found in the storm water management phase. A 50\% cost savings would be achieved by the following simple actions: 1) Omission of curb and gutter in strategic areas; 2) Reduction in the amount of pipe required as well as reduction in their lengths and size; 3) Reduction in the need for inlets to underground pipes; and 4) The introduction of smaller rain gardens throughout the community to replace the one large retention pond.

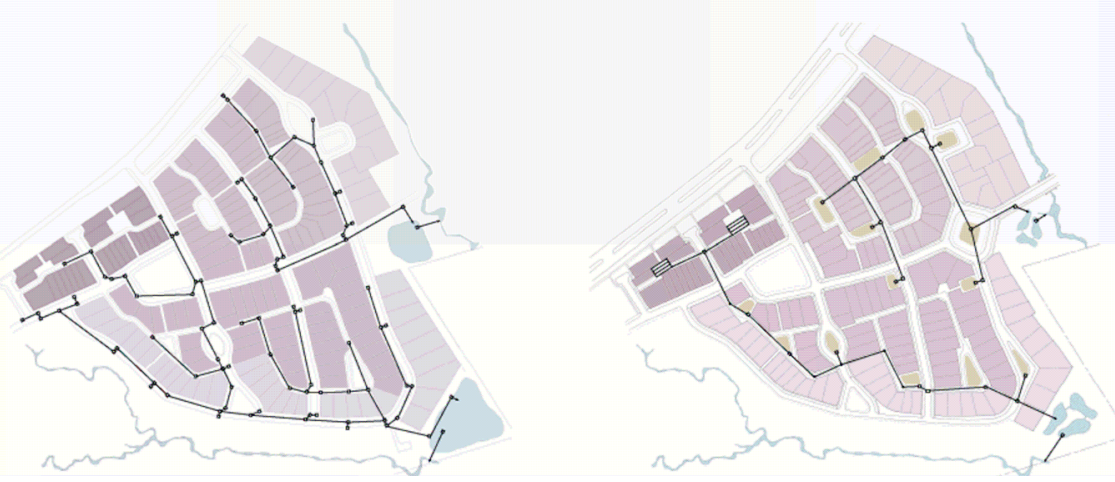

Figure 3: Engineering infrastructure of Griffin Park, left image represents Conventional TND Master plan and the right image represents Light Imprint TND Master Plan.

The figure above shows the engineering infrastructure for each of these plans. The introduction of rain gardens also adds aesthetically pleasing natural areas and neighborhood recreation areas. Rain gardens would remove a greater amount of pollutants from runoff before the pollutants could reach the Reedy River. The rain gardens permit groundwater recharge, thus contributing to the restoration of the natural water cycle. Also, there are two road pavement issues that reduce costs. First, building 24 feet wide roads instead of 26 feet wide roads results in a significant reduction of land coverage and paving costs. Second, substituting crushed stone in place of asphalt-paved alleys saves over $20 \%$ in development costs. Significant attenuation and improvement in water quality can be achieved by permeable pavements. Implementing the light-imprint engineering method results in over $30 \%$ cost savings in actual construction dollars for the first phase. 
That cost saving is in addition to the added value realized by the preserved mature trees and communal rain gardens.

Another example which will provide the Low Country with a viable alternative to suburban sprawl is Habersham, SC located south of Charleston. The town is positioned along the marshes of the Broad River, less than a mile from the intercoastal waterway. With its sizable town center, Habersham will serve as the urban hub for surrounding villages. The architecture of the project respects the local vernacular, taking into account the expert methods employed by traditional designs for ventilation and cooling. The building types are designed and located on the plan according to their levels of urbanism. Along with the different street sections, the broad assortment of building types will provide a varied and authentic environment. This permits a single development to capture a wide variety of home-buyer market segments. In addition, the compatibility ensured by the code maintains high property values and the flexibility of switching to the most marketable building product without redesigning the entire plan. Winner of the 2004 Platinum Award in the Best in American Living (BALA) Competition, sponsored by Professional Builder magazine and the National Association of Home Builders.

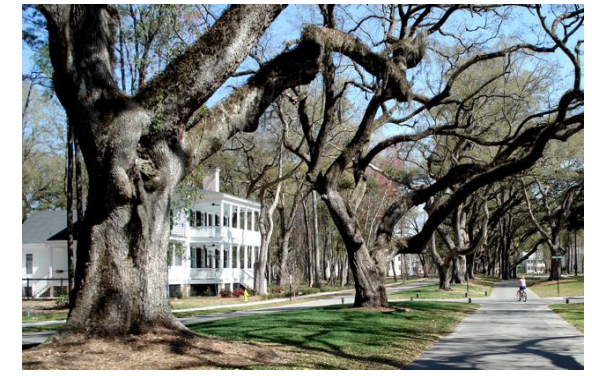

Figure 4:

$\begin{array}{lr}\text { No curb } & \text { LINU } \\ \text { boulevard } & \text { in }\end{array}$
Habersham, SC.

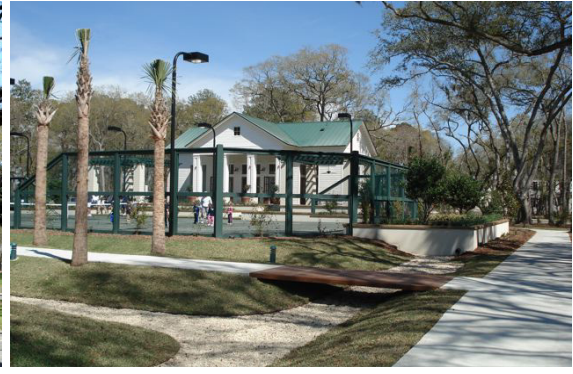

Figure 5:

A built example of Light Imprint storm drainage, Habersham, SC.

A comparison between the two engineering methods based on erosion control measures, storm water infrastructure, and pavement width and materials for the first phase of the development of 42 acres and 174 lots shows about a 30\% lower cost for the LINU method. For Griffin Park, the LINU case study for the first phase was compelling enough to lead the development team to apply LINU techniques even after the construction had started. The application of the LINU methods based on transect zones can be further applied to reduce the impact on watersheds on a larger regional scale. The LINU strategy allowed more storm water surfaces to encourage onsite adsorption and to reduce the typical number of drain inlets and the length of the drainage pipe system. The introduction of rain gardens allowed for enhanced natural biodegradation of pollutants from runoff. Additionally, the lots and streets along the neighborhood perimeter did not need most of the swales since a portion of the storm water was sheet flowed through the filtration landscaping directly into existing natural drainage systems. 
The Light Imprint model is a comprehensive strategy which supports the New Urbanist design of street and lot layout along with other standard practices for common infrastructure elements including water and sanitary sewer. For Light Imprint New Urbanism, engineering hydrology becomes critical. The surface and subsurface infrastructure can remove both the soluble and fine particulate pollutants that occur within urban runoff. However, soil analyses are needed to verify that soil is in compliance with rain garden absorption requirements and to confirm that smaller pipe size is sufficient for the system. If pervious road surfaces are being considered for alleys, lanes, and streets without curb and gutter, then measures are needed to stabilize the road and alley shoulders to prevent soil erosion and tire rutting. The LINU strategy of allowing more storm water surface sheet-flow across pervious surfaces to encourage onsite absorption and to reduce the typical number of drain inlets and length of drainage pipe. Additional ways for reducing the infrastructure includes sheet flowing the stormwater through the filtration landscaping directly into existing natural drainage systems, thus eliminating swales for some lots and streets along the neighborhood perimeter. Roof water can be piped into the storage area directly, adding areas from which the flow can be attenuated. Light Imprint New Urbanism offers a more manageable alternative by coordinating innovative engineering practices with the New Urban design approaches in specific transect zones.

\section{Conclusion}

LINU offers a planning alternative which lies lightly on the land; preserves mature tree stands; and lowers the construction and engineering costs without compromising design priorities such as connectivity and the public realm. These techniques allow best protection of the watershed hosting this development by maintaining the land in its natural condition and minimization of the impervious cover. The most compelling factor for using the LINU design principles is the improved affordability of the community by an overall decrease in construction costs. The Light Imprint development strategy resulted in a 27 percent cost increase, with the introduction of tree protection fences. Yet, an overall of 50 percent cost savings occurred with: 1) The reduction of curbs and gutters; 2) The reduction in the number of storm water pipes and inlets; 3) The reduction in pervious pavement in alleys and streets; and 4) The introduction of rain gardens. The LINU framework enhances existing urban sustainability practices and promotes preservation of watersheds on a large regional scale. LINU provides a solution to the most difficult planning and engineering question about how to preserve and restore the natural resources and services derived from the watershed while ensuring human well-being.

\section{References}

[1] Unitest States Environmental Protection Agency. (2000). Low Impact Development. Washington, DC 20460: Office of Water. 
[2] Prince George's County, M. (1999). Low-Impact Development Design Strategies, An Integrated Design Approach. Largo, Maryland 20774: Department of Environmental Resource, Programs and Planning Division.

[3] Nisenson, L. (2005). Using Smart Growth Techniques as Stormwater Best Management Practices. Retrieved March 2007, from Smart Growth: Stormwater Best Management Pracices: http:/www.epa.gov/smartgrowth/ pdf/sg_stormwater_BMP.pdf

[4] Long, S., Tachiev, G., Yaari, G. (2007). A GIS Study of the Effect of Population Density on Urban Infrastructure. Miami: Energy Environment Sustainability Center, Florida International University

[5] US Census 2000, Population data retrieved March 2007 from http://www.census.gov/main/www/cen2000.html

[6] LINU www.lightimprint.org, visited March 2008 